Research Article

\title{
National Statistical Management System: Opportunities, Challenges and Future Steps
}

Manish Thapa ${ }^{\mathrm{a}^{*}}$

a. School of Education, Kathmandu University, Lalitpur, Nepal

Manuscript Received: March 20, 2021

Final Revision: August 23, 2021

Accepted: August 29, 2021

\begin{abstract}
Globally, countries adopt either centralized or decentralized statistical management system. With over 60 years of history, Nepal has been practicing decentralized statistical management system where various government agencies alongside non-government and private agencies manage statistics based on their needs and requirements. Statistics Act 1958 set the foundation for statistical management system, that is in operational stage as of 2021. This paper sets an objective of reviewing the legal instruments associated with statistical management system and explores the opportunities and challenges of integrated statistical management system. Paper adopts systematic literature review method to search, sort and filter the relevant literature associated with opportunities and challenges of statistical management systems and/or practices. The adoption of statistical management system among countries were found to be varied (centralized/decentralized) based on the countries' needs, interests, capacity to set-up infrastructures. Hence the paper recommends updating the statistics related legal instruments and emphasizes the establishment of single institution. Based on which, country can adopt the principle and modality of either centralized or integrated statistical management system based on its needs and interests. After identifying the complexity, privacy, confidentiality, safety and security associated with integrated statistical management system, the paper suggests laying out a foundational framework for a strong and effective system. Afterwards possible concerns could be addressed through updated statistical acts and rules.
\end{abstract}

Keywords: government, legal instruments, service delivery, integrated statistical management, policy

* Corresponding author; E-mail: gambhir2046@gmail.com, C)Author(s)

Published by Nepal Public Policy Review and peer-review under responsibility of Policy Research Institute Nepal. Licensed under CREATIVE-COMMONS license CC-BY-NC 4.0

(C) (i) (5) 


\section{Introduction}

Statistical management system is one of the core aspects of development for any country. Strong statistical management practices provide an enormous opportunity for planners to analyze theme-wise data and plan accordingly (Alghamdi et. al., 2011; Hilbert, 2016). At the global level, the modality of statistical management system largely varies based on the interest and priorities, availability of human resources, technological and financial resources. The main objectives of statistical management systems are twofold: first, the record keeping of national citizens namely vital event registration and national ID, second maintaining sectoral statistics. Both sets of statistical management system are developed or established to serve the national need of delivering public services and engage in evidence-based planning (ADB, 2016; Aritonang, 2017; Khan, 2018; Mohammed et. al., 2016; Piotrowicz, 2015; Soja \& Cunha, 2016; Szabó \& Chiriac, 2016).

National needs and priorities enforce countries to either adopt integrated statistical management system or sector based statistical management system. Sectoral based system, also known as stand-alone or component-based statistical management system, is managed under specific statistical guidelines. These guidelines vary between institutions based on their plans, policies, strategies and objectives. In such a system, all the statistical management practices are done by different institutions which may or may not inter-link with each other. This necessitates the need for individual specific or sector specific data collection. With different institutions (government, private and I/NGOs) collecting same information without an interlinking system, concerns of duplication (cost, time, and resources), confidentiality, privacy and their misuse is a global concern. To reduce the issues associated with duplication, data security, and to strengthen the e-governance system, technologically advanced countries have been practicing various versions of integrated statistical management system.

To maintain an effective integrated statistical management system, governments must spell out periodic strategic plans and establish centralized server which can be further accessed by government agencies, private agencies, I/NGOs as well as civil society to some extent.. Policy formulation to set-up, implement and monitor the effectiveness of an integrated statistical management system is the key initial task that get carried out by respective countries. At the implementation level, governments set-up a mechanism to provide unique identifier to each individual and conduct data collection. The depth of individual-specific data collection system rely on country-specific system and objectives (Gelb \& Diofasi, 2016). Government and nongovernment agencies link unique identifier to their statistical system, plans and service delivery such as health service, academic institution service, financial transactions, government services, transportation services, personal cards such as license, passports, etc. (Alghamdi et. al., 2011). In an integrated statistical management system, diverse government agencies rely on a single system, analyze existing information, and form plans and focused programs based on their respective institutional objectives.

Nepal has a long history of managing statistics but in the stand-alone or component-based system, that is individual and sector-specific separately through different government agencies. The concept of integrated statistical management system is brought forward for discussion; however it is yet to be materialized due to the lack of policy focusing on integrated statistical management system. Based on Statistics Act 1958, Central Bureau of Statistics (CBS) has been

\section{Page 88}


updating sectoral database and carrying out census. Starting with the first five-year plan (195661) the government has prioritized towards strengthening the national database and statistical system. Thereafter, citizen (individual) related database has been updated since the promulgation of Birth, Death and Other Personal Events (Registration) Act 1976 \& Rules 1977. United Nations Fundamental Principles of Official Statistics: Implementation has been adopted to manage and update national database.

In the current context, the need for stronger statistical management system and integration of information is incorporated into diverse set of legal instruments and periodic plans in a scattered manner. Thus it has not been prioritized or emphasized by neither government nor private agencies (Subedi, 2020). The lack of integrated system has adverse effect at various levels of both government and non-government agencies. The existing requirement for a survey by each organization based on their respective objectives has resulted in duplication and waste of resources among agencies. Individual di-trust towards data collection process have also been observed in some cases in the recent days (Shrestha, 2019; Verhulst \& Young, 2017).

To resolve the issues of identification, tracking as well as to respond to the needs of individuals, many countries across the world have already started moving towards promulgation of policies in order to support and set up the integrated system. Under this system, with detailed entry of information into the system, individuals are provided with a unique ID or identifier, that is linked with sector-specific statistical management system, (Phuyal, 2020). The process of promulgating such policies and adopting such system is taking a momentum after technological advancement and national commitment to provide legal identity for all by 2030; this also aligns with Sustainable Development Goal 16.9 (Brewer et. al., 2015; Gupta \& Vegelin, 2016). Barring some challenges, the scenario of verification-based integrated statistical management has worked for countries to identify, track and respond to the needs of the public. Though Nepal already initiated providing national ID, this has yet to be effectively implemented as country still lagged behind in terms of infrastructure and resources (financial, human and technological). Thus, disconnection between data availability and government/non-government decisionmaking process and plans is one of the most frequently raised issues in Nepali context. This paper focuses on reviewing the strengths of centralized or integrated statistical management system and pointing out underlying challenges and the key areas to be incorporated in national legal instruments (policies, guidelines and strategies).

The objective of this paper is twofold. First, to explore opportunities and challenges associated with the current statistical management practice of Nepal. Second, to review the existing legal instruments (act, policies and strategies) and make recommendations for integrated statistical management policy for Nepal.

\section{Research Strategy}

The study adopts systematic literature review method, where articles written between 2000 and 2020 are taken into consideration. As the study revolves around the statistical or database management system, combination of key words such as "national statistics", "national database", "registration system", "opportunities", "challenges", "strength", "best practice", "issues", "benefits", "integrated" and "weakness" were searched into the database of google scholar. Considering the high number of documents with any of those combinations, documents most relevant to the study's objective were screened. Documents without any 
reference to subject area were removed. Selection process emphasized on reviewing the documents that could point to the statistical management practices and/or civil registration and vital statistics in the Global context as well as specific context of Nepal.

Legal instruments such as act, policies, plans, strategies and guidelines associated with statistics, civil registration and e-governance were reviewed to explore the existing strength and gaps.

Table 1 List of document supporting statistical management system

\begin{tabular}{|c|c|}
\hline Constitution & Constitution of Nepal 2015 \\
\hline Act & $\begin{array}{l}\text { Statistics Act } 1958 \\
\text { Birth, Death and Other Personal Events (Registration) Act } 1976 \\
\text { Local Government Operation Act } 2017\end{array}$ \\
\hline $\begin{array}{l}\text { Rules and } \\
\text { Regulations }\end{array}$ & $\begin{array}{l}\text { Statistics Rule } \\
\text { Birth, Death and Other Personal Events (Registration) Rules } 1977\end{array}$ \\
\hline Strategy & National Strategy for the Development Statistical System 2018-2023 \\
\hline Plan & $\begin{array}{l}\left.\text { Periodic Development Plan ( } 1^{\text {st }} \text { Plan }-15^{\text {th }} \text { Plan }\right) \\
\text { Consolidated National Statistics Plan } 2000\end{array}$ \\
\hline Directives & $\begin{array}{l}\text { National Information Technology System Directive } 2014 \\
\text { National ID Program Implementation Directive, } 2020\end{array}$ \\
\hline Framework & 2019 Digital Nepal Framework: Unlocking Nepal's Growth Potentia \\
\hline Fiscal Year Budget & Fiscal Year Budget from FY 2016 to FY 2021 \\
\hline Guideline & $\begin{array}{l}\text { United Nations Fundamental Principles of Official Statistics: } \\
\text { Implementation Guideline, } 2015\end{array}$ \\
\hline
\end{tabular}

\section{Results and Analysis}

\subsection{Statistical Management Practices in Nepal}

Nepal has over 60 years old history of statistical management officially started with the establishment of Central Bureau of Statistics (CBS) under Statistics Act 1958 (Phuyal, 2020). CBS carried out its first agriculture statistics (1961) within its first five-year period of establishment. As of 2021, Central Bureau of Statistics (CBS) in coordination with various ministries collect, interpret, analyze data. It also publishes sectoral reports such as Population censuses, Food and Livestock Survey, Nepal Living Standard Survey, Nepal Labor Force Survey, Censuses of Manufacturing Establishment, Demographic Health Survey, Economic Survey etc. (Dennison \& Rana, 2017; Phuyal, 2020). With the approval of CBS, other government and non-government agencies have been carrying out statistical management system based on respective needs. Registration of vital events started in 1977 after promulgation of birth, death and other personal events registration Act 1976. The registration process was first piloted in 10 out of 77 (then 75) districts and later in 1990 it was made nationwide (Gautam, 2016). As of 2021, department of national ID and civil registration is the responsible agency to process national ID and register vital events through digital as well as paper-based medium.

\section{Page $\mid 90$}


The concept of developing integrated statistical system was previously recognized with the establishment of National Statistical Council (NSC). However, citing multiple reasons, the concept of integrated statistical system was not materialized until 2015, when Constitution of Nepal mandated the integrated identity management system under article 15 . The concept of integrated statistical management system has been detailed out on Local Government Operation Act (LGOA) 2017, $15^{\text {th }}$ periodic plan (2018/19-2023/24) and annual plan for the fiscal year 2021/22. With Federal structure in place, LGOA 2017 mandated the need of updating statistics or database under the responsibility of local level (Subedi, 2020). National Strategy for Development of Statistical System (2018/19-2022/23) envisions the use of updated technology to improve the qualitative aspects of data collection practices in Nepal (National Planning Commission [NPC], 2018). It also emphasizes on strategically formulating legal instruments to support government institutions at different levels in having a system which are either centralized or linked with each other to act as the platform for further planning and budgeting.

To strengthen national statistics and civil registration process, National ID and Registration Act 2019 mandated the need of ensuring each citizen get National ID along with an establishment of integrated national ID management information system. The Act also mandated the need of aligning civil registration system with government services, national development plan and security system. Though the Act mandated the need of integrated database with multiple objectives, it has excluded the role of CBS or National Planning Commission (NPC) which are among the key government authority responsible for development of related database. Exclusion of CBS or NPC from responsibility made the Act weaker as all other sectoral ministries aligned themselves with CBS or NPC in terms of statistical management and evidence-based planning.

\subsection{Legal Instruments to Support Statistical Management Practices}

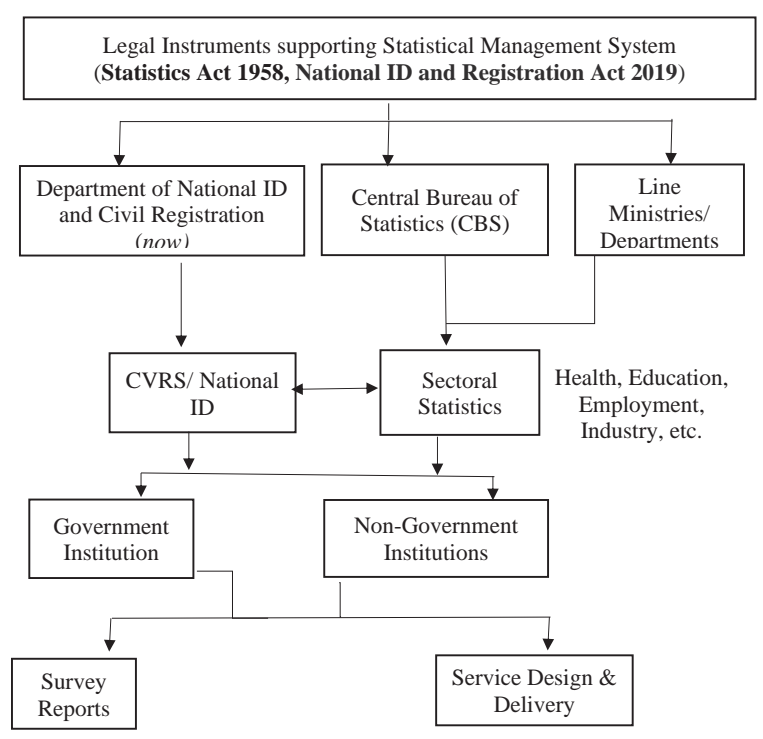

Figure 1 Operationalization Process of Statistical Management System (Contextualized)
Statistics Act, 1958 and Statistics Rules 1984 paved the way for statistical management at official level in Nepali scenario. Under the provision of Statistics Act, Central Bureau of Statistics was established, which is actively collecting, compiling and presenting the statistical scenario of diverse sector agriculture, economy, industry, tourism, etc. The Act emphasizes on collection, compilation, and publication of statistics. It also details out the provision of their usage and the penalty system associated with misuse. The Act has not talked much about the quality of statistics, their consolidation mechanism 
and repository system. With digital revolution in the $21^{\text {st }}$ century, the Act is yet to be updated to accommodate the provisions of digital engagement and associated concerns of safety, security, privacy and confidentiality. With the permission of CBS, organizations (government or non-government) could establish their respective statistical management systems. Separate statistical management practices in the form of Census (under CBS), Health Information Management System (under Ministry of Health and Population), Education Information Management System (under Ministry of Education, Science and Technology) exist in the government sector. Data collection practices also exists among some I/NGOs . Overall, this practice has resulted into multiple and scattered statistical management system.

Birth, Death and Other Personal Events (Registration) Act 1976 \& Rules 1977 was promulgated to initiate the registration process of vital events, which includes birth, death, marriage, migration and divorce. The Act detailed out the responsible person and institution to register personal events and also laid out the provision of penalties for potential misuse or false information. It also required the local level institutions to share registered personal event on a monthly manner. Even though the concept of e-governance was widely discussed during the time, the significance of adopting technological tools to register and share the registered personal events in real-time was not provisioned in the Act. As of 2021, Birth, Death and Other Personal Events (Registration) Act and Rules have been replaced with National ID and Registration Act 2019.

Consolidated National Statistics Plan (CNSP) 2000 details out issues, challenges and gap areas along with the recommendation to rectify the identified issues/gaps in eight different statistical systems focused on agriculture, social sector, demographics, labor and employment, industry, public finance and national account. CNSP incorporated the statistical calendar for 2000-2005, where all the data collection or survey related activities were listed alongside the major statistics to be extracted from those data collected. Though, such type of plan/strategy was developed for the first time when the significance of maintaining an integrated statistical management system was not considered. Rather, the sector wise statistical plan was emphasized and presented in a calendar form.

National Information Technology System Directive 2014 provisioned the government institutions to set-up and have information technological system in place. The directive mandates the government institution to maintain uniform information technological system. The directive detailed out the provision of accessing the system through multiple institutions based on their needs and requirements. It went a step ahead with an inclusion of key aspects of privacy, confidentiality, security, infrastructure set-up for back-up and archiving. These aspects were not intensively included in previous legal instruments.

Constitution of Nepal 2015 incorporated the aspect of right to information and right to privacy. In the right to information, each Nepali individual does hold a right to access information of public interest. Meanwhile, right to privacy ensured the civil right to maintain privacy of their personal information including personal event related information. The requirement to update national statistics and use them for national development plans alongside the integrated national identity management information system and their use to deliver government led services and facilities is recognized and addressed by Constitution of Nepal 2015. Enlistment of "collection of local statistics and records" under the local level paved a path for initiating the integrated or consolidated statistical management system at local level.

\section{Page 92}


However, the current practice of maintaining sector-specific statistical management system could pose a challenge in setting-up an integrated statistical management system at local level.

Local Government Operation Act (LGOA) 2017 provisioned context-based plans and policies at the local level. It includes the requirement of collecting and managing statistics at local level and using them appropriately for local level budgeting and planning processes. The existence of separate statistical management policy at each local government could create a scenario where, each LG have their respective statistical management system that are nonidentical and non-uniform to each other. This could create a challenge in compiling and publishing nationwide statistics as directed by Statistics Act 1958 for Central Bureau of Statistics.

National Strategy for the Development of Statistical System (NSDSS) 2018/19-2022/23 sets the vision of establishing well-coordinated, functional and strong national statistics system. NSDSS strategizes to develop statistical system aligning with federal structure, managing the statistical arrangement ensuring their reliability and quality and strengthening the institutions responsible for statistical management. By 2020, countries have adopted diverse set of statistical management systems based on their needs/priorities, available human resources, technological advancement and financial capacity. NSDSS indicates towards upgrading national statistical management system, however it has not indicated the possible modalities that could be adopted based on success/failure of global practices. NSDSS focuses on having statistical management system at different levels, that is, local, province and federal. However, the need of maintaining integrated system alongside their safety and security is not prioritized. NSDSS emphasizes on setting-up institutions for appropriate statistical management at different levels such as National Bureau of Statistics, National Statistical Training and Research Centre and dedicated statistical units at local and province level. However, the status of institutions currently managing sector-based statistics is not addressed.

From technological advancement perspective, 2019 Digital Nepal Framework paved the pathway for government authorities to shift towards adoption of digital technologies to deliver their respective services. This framework emphasizes on eight sectors namely digital foundation, health, agriculture, education, energy, tourism, finance and urban infrastructure and identifies three prioritized areas namely technology and infrastructure, private sector participation and talent and skill development. Areas incorporated in the framework are also the major areas where CBS intensively engages in having periodic and systematic collection of data/statistics. Thus, the identified priority areas could play significant role in upgrading the existing infrastructure and scaling to local level, authority to update statistics as mandated by Local Governance Operation Act (LGOA) 2017.

Strategy of Civil Registration and Vital Statistics (CRVS) 2019 was developed with an objective of intensifying the civil registration and vital statistics related works aligning with commitment of government towards achieving international goals. The strategy sets the vision of having technology friendly advanced information management system for civil registration and statistics management. Strategy details out the possible linkage between existing civil registration mechanism with other sectors in order to present the progress made by Nepal on global (SDG's) indicators. One of the action plans is to coordinate with institutions responsible for census to include civil registration and vital statistics during census itself. 
National ID and Registration Act 2019, Rules 2020 provisions the need of functional national ID management information system. National ID and Registration Rules 2020 details out the process and requirements to acquire national ID and the types of details that are incorporated into national ID. As the national ID includes details such as nationality, birth, migration, marital status, occupation, education and information of parents, it provides an opportunity to link the national ID management information system with other statistical management systems under government-led institutions especially under Central Bureau of Statistics. As the registration process envisions the use of digital medium to initiate registration process, the integration of government-led statistical system could be the possibility. National ID and Registration Rules 2020 mentions the sectors such as passport, land, vehicle registration, vital event registration, social security, tax, citizenship and other areas as identified by the government. These aspects could play a pivotal role in initiating the establishment of integrated statistical management system as envisioned by Constitution of Nepal 2015.

National ID Program Implementation Directive 2020 was prepared based on National ID and Registration Act 2019 to guide authorities on implementing National ID project. It mandated the need of establishment of unit at District Administrative Office (DAO) to collect, document and distribute national ID. The directive provisions both digital as well as manual practice for an application of national ID. During an application process itself, applicant (national citizen) needs to detail out the demographic information. The directive, however, fails to address approaches to be adopted to ensure the safety, security and confidentiality of the collected data. Coordination committee is envisioned at district and national level but with federal system most of the powers are already delegated to Local Government. In this case, the role of Local Government to facilitate the registration process is neglected. As the whole program itself largely depends on the digital system, an exclusion of representative from Ministry of Communication and Information Technology could play crucial role in near future.

\section{Periodic Development Plans:}

First plan (1956-1961) included cadastral survey to collect agricultural and land related statistics. Lack of statistics was largely felt on sectors such as commerce, tourism, industry and trade which limited the government's effort to formulate evidence-based plans. Identifying the gaps, the plan emphasized on having sector specific statistics as well as vital statistics. Third plan (1965-1970) focused on having strategic and meaningful statistical management system with an objective of making data available to individuals and institutions. The Plan focused on making data and information accessible to public through statistical publication. Detailed report of population census and agricultural census was published. Collection of vital statistics was expanded across the country. Fourth Plan (1970-1975) initiated the process of standardization, coordination and mechanization to make the statistics more reliable and dependable. Plan attempted to address the issues of duplication associated with the collected statistics through multiple government institutions. Sixth Plan (1980-1985) strategized to make development plans more practical and effective with an input of reliable and updated statistics. Furthermore, the updated statistics were utilized for formulating policies and programs. Fifth plan (1975-1980), sixth plan and seventh plan (1985-1990) were more about adopting technological tools to collect, compile and analyze statistics by setting up infrastructures and training human resources. These plans utilized updated statistics to formulate short-term and

\section{Page 94}


long-term plans. National Statistical Council (NSC) which facilitates the process of collection, compilation and analysis of statistics was established. Several surveys namely agricultural census, industrial census, population census were carried out and published during the Eighth Plan (1992-1997).

The provision of sharing statistics to national and international organizations were advanced during the Eighth plan period. Furthermore, the plan highlighted the need of conducting periodic household level survey to update socio-economic status and improve survey technique. Ninth plan (1997-2002) was among the key development plans that expanded the computerization process of recording civil service related data. Meanwhile, the records were consolidated and combined with central record. This plan emphasized on collection, analysis and update of local level statistics. Tenth plan (2002-2007) incorporated the strategies to make statistics authentic, reliable and user-friendly. Furthermore, it intensively formulated action plans to carry out multiple surveys and make them periodic, comparable and also worked towards reducing the duplication in statistics. Eleventh Plan (2007-2011) strategized to strengthen the two institutions responsible for statistical management, namely National Planning Commission (NPC) and Central Bureau of Statistics (CBS).

Continuing the progress from previous periodic development plans, $12^{\text {th }}$ plan (2011- 2013) worked towards strengthening the statistical management system from national to local level. It envisioned the establishment of Geo-information System to store the statistics in central manner. Thirteenth plan (2013/14 - 20154/16) envisioned the development of central statistics to upgrade statistical management system. It worked on having coordinated national statistical system to regularize statistical and approval system. It also discussed the need of standardizing statistics based on international standards. Fourteenth plan (2016/17-20418/19) focused on result-based statistical production and their usage for planning and policy making. Plan introduced the concept of national statistics training and investigation center along with the formation of inter-ministerial or inter-departmental statistical acting group. The survey to have baseline value for the indicators as stated in Sustainable Development Goal (SDG) was carried out. Fifteenth plan (2019/20- 2023/24) envisioned the national statistical profile to incorporate integrated data and indicators in order to make statistics accessible and available to local level. Plan strategizes of making standards, formats and classifications as per globally recognized templates and formats. The use of modern information and communication technologies has been mentioned in the plan but the type and mechanism of usage has not been well elaborated. To put the uniform and consistent statistical management system in place, the fifteenth plan includes the strategies to upgrade the capacity of local levels and establish a basic system of data management at local level.

\section{Annual Budget and Programs:}

Prior to the annual budget and plan for Fiscal Year (FY 2018/19), statistics related plans used to be incorporated within the sectoral plans and programs. However, budget for FY 2018/19 specifically highlighted the need of having think tank to provide reliable, contextual and implementable statistics to the government for preparing annual plans as well as short-term and long-term plans. Similarly, budget was allocated to carry out initial works for population census, household survey and agricultural survey. A separate section was included in the budget to state annual plans and budget to carry out statistics related activities. The same trend 
thereafter follows till current plan (FY 2021/22). FY 2019/20 highlighted the open statistical system by allocating budget for the same. Continuing to previous fiscal year's budget, it also allocated the budget for population census, agricultural survey, multi-indicator survey, household survey and industrial survey. FY 2020/21 emphasized on the need of having reliable statistics for policy development and decision making, thus included the plans to strengthen institution. Continuing the previous trend of allocating budget to carry out census, household survey, agricultural survey and industrial survey, Fiscal Year (FY) 2021/22 also added some budget to carry out the remaining works. Most importantly, annual budget includes the plans to integrate the existing statistical management system and focus on establishing safe repository mechanism alongside the capacity development to analyze big data. Similarly, the implementation of open statistics was also included as prioritized plan.

United Nations Fundamental Principles of Official Statistics: Implementation Guideline 2015 details out the principles that support having a strong national statistical system. The guideline provided recommendations to ensure the independence of national statistical systems. It also guides countries to set up the foundation for respective national statistical system in areas of accountability, transparency, legal processes, confidentiality, safety, security, relevancy, and accessibility. For each identified areas, the guideline details out best practices among diverse national statistical system.

\subsection{National Statistical Management Practices at Global Level}

Globally, countries have been adopting various forms of citizen registration systems alongside sectoral statistical management system with an issuance of unique identifier cards depending on their local needs, priorities, and capacities (Gelb \& Diofasi, 2016). Eighteen percent of developing countries have system for single purpose meanwhile, 55 percentage of countries have used for specific function and services ranging from cash transfers to health. Statistical management system adopted by diverse countries across the globe is basically categorized into centralized or decentralized statistical management system. Depending on the national needs, priorities, requirements, capacity, infrastructures and end-use, countries preferred to have either centralized or decentralized statistical management system. Both set of systems have their own respective advantages and disadvantages (United Nations, 2021). Centralized or integrated statistical management system tend to have specific and clear set of rules and policies setting out the foundation for confidentiality, independence and impartiality. Coordination and collaboration within the departments ease decision making process. Quality assurance of national statistics further makes data reliable and usable for evidence-based planning process. Countries such as Pakistan, Peru and India have centralized system emphasizing registration and identification services. Whereas, countries such as Mexico, Nigeria and Tanzania have multiple systems in use in a parallel manner (United Nations Children's Fund, \& United Nations Economic and Social Commission for Asia and the Pacific, 2019; The World Bank Group [TWBG], 2017). Establishing an effective national statistical system mainly relies on relevance of statistics for societies, technical qualification and independence of leading institution responsible for managing national statistics and the relationships of national statistical system with wider range of stakeholders (Quintslr, 2015).

Malaysia adopted a system entitled MyKad which is used for identification, verification purpose as well as for accessing government services and day to day transportation services (Salman, 
2010). Indonesia has electronic identity card termed as e-KTP which allows the government for effective implementation of their services, conducting census, controlling security threats as well as issuing driving licenses, insurance policies, taxpayer certification and other identity related documents (Priyantu, 2012). Singapore adopted centralized identification system, where citizens are required to provide detailed information through which they can access services at government or private institutions. In other words, it has helped to eliminate duplication in information collection system (Asian Development Bank [ADB], 2016).

Indian Statistical System is operating at varied level with both horizontal and vertical division across the government units. Data and information from national statistical system get used for decision making process of public and private institutions. Furthermore, the statistics are easily accessible to individuals and institutions (Radhakrishna, 2012). India's Aadhaar card system which is also one of the largest digital card systems eased the process of accessing government services and subsidies (Barde, 2018). Through the national ID system, citizen of Pakistan can access wider range of government and non-government services such as registration at academic institution, health institution, banking services, telecommunication services, transportation services, financial and land transactions, etc. (Ullah et al., 2015). Belgium practices e-ID card system which allows citizens to access public services, link with tax declaration, register at public libraries and community services (Arora, 2008). Biometric identification along with smart cards are in use in case of South Africa through which government authorities provide social protection and support to their citizens (Breckenridge, 2005). Nigeria adopted colonial statistical management system where single statistical institution is made responsible to manage national statistics. Nevertheless, it does have focal person in each of the major government institutions. The provision of a focal person helped in harmonization of data and made them efficient (Geteloma et. al., 2019; Olubusoye et al. 2015). Thailand government approved Digital ID bill to link users (citizens) from multiple institutions (Greenleaf \& Suriyawongkul, 2018). Philippines is in planning stage for adopting digital ID through which government can prioritize the minorities during planning and citizen can access government services as well as link with economic sector (job) and financial sector (registration at banks) (The World Bank Group, 2017).

\subsection{Opportunities of Integrated Statistical Management System}

From citizen to policy makers to institutions (government and non-government), integrated statistical management system based on integrated statistical management policy provides diverse benefits to all.

\section{Shifting from Paper-Based System to Digital System:}

In recent times, government institutions have started documenting individual and family related information in digital manner. Series of capacity building sessions have been held from federal level to local level after an introduction of national ID card system. However, the progress is limited. Though, there are plans to integrate national ID with other government provisioned services, it has not yet been fully executed. As the ID number contains series of crucial background information, government as well as private institutions with authority to access details of national ID need to mandatorily adopt digital registration system (Dass \& Bajaj, 2008; Mitra, 2019). As one of the objectives of integrated statistical management policy is to bring together government services and facilities under single platform, their adoptability 
towards Information, Communication and Technology (ICT) further enhances the e-governance status of the country (Rokhman, 2011).

\section{Evidence Based Inclusive Programming:}

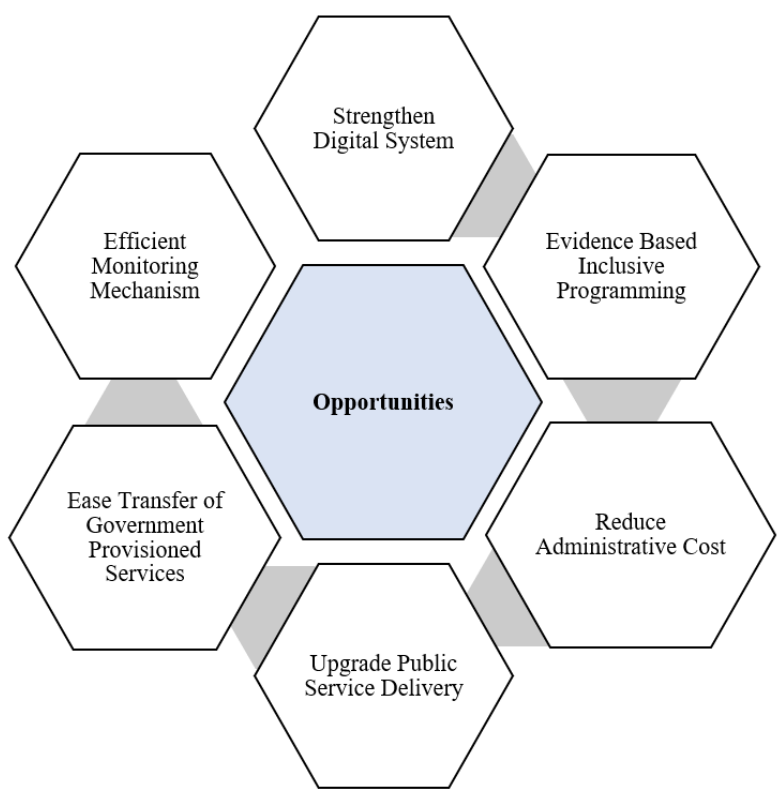

Figure 2: Opportunities of Integrated Statistical Management System
With federal structure in place, government institutions are developing plans and programs to adopt consultative approach from community to local and federal level with participation of key stakeholders and communities. However, none of the programs are developed based on statistical evidence but are based on observations and interactions. With integrated statistical management policy in place, each local government can contextualize and develop the guideline to have statistical presentation of digital information (Hilbert, 2016). Evidence based programming helps to identify real need of communities and individuals and implement them in effective manner as well (Atick, 2016).

As integrated statistical management system incorporates detailed information regarding the areas and individuals accessing government and non-government services alongside their frequency and intensity, government can plan accordingly to prioritize more among the individuals and communities which are usually excluded from receiving government services (Atick, 2016; Hilbert, 2016; ADB 2016). Either it be development-based programs or response packages, integrated statistical management system based on integrated statistical management policy can help to track the excluded groups and incorporate them in forthcoming plans and programs (Brewer et al., 2015; Mitra, 2019).

\section{Effective Public Service Delivery:}

In an annual manner, government from federal to local level has been planning and implementing dedicated programs to empower excluded, marginalized and vulnerable groups (Giri\& Shakya, 2019). Barring the social protection related activities, there has been voices of dissatisfaction towards targeted programs. With integrated statistical management system in place, the probability of reaching out the targeted groups to provide dedicated services increases (ADB 2016; Bertot et al. 2016; Sarker et al. 2018). The case of wrong person receiving the government services in the name of targeted groups gets reduced or eliminated as the 
digital system can efficiently track the individuals benefitted from targeted programs (Oracle 2008; Peeters \& Widlak 2018).

\section{Ease Transfer of Government provisioned support and services:}

It has been evident that the social protection related programs have been effective once the system was made digital and linked with financial institutions (Giri \& Shakya, 2019). Firstly, targeted groups received the services. Secondly, the whole transfer of services was smooth and timely (Mitra 2019; Rokhman 2011). Citizens eligible for receiving the services can easily access the services as per their convenience from allocated financial institutions. With right tracking and monitoring system in place, implementation of other dedicated programs such as subsidies, grants, scholarships, cash transfer, etc. can be accomplished in a timely and efficient manner further increasing transparency and trust among citizen.

\section{Efficient Tracking or Monitoring Mechanism:}

With integrated system in place, the government authorities implement targeted and inclusive programs in a timely and efficient manner as well as can generate evidence to claim the effectiveness of programs (Hilbert 2016; Peeters \& Widlak 2018). Government can get clear idea on individuals receiving the benefits. Either it be for ad hoc response activities or regular subsidies, grant and scholarship related activities, government authorities get an opportunity to track the potential beneficiaries and ensure right beneficiary got the support further strengthening the tracking and monitoring mechanism of government (Bertot et al. 2016).

\section{Reduces administration cost:}

In current scenario, citizen need to fill-up the same information in every single form either it be government or private. With the implementation of integrated statistical management policy citizens can only provide ID number instead of complete information to data collecting agency (Atick, 2016). While doing so, time and resources of both citizens as well as institutions are optimally utilized further increasing efficiency of service delivery (Alsheshri et al., 2013). Sector-wise survey or census is costly compared to integrated statistical management system (Kitchin, 2015). In the latter, majority of the costs occurs during initial phase due to infrastructure set-up and capacity building. With continuous use of same system and periodic updates based on national needs and priorities, the long run cost goes down. Hence, integrated statistical management system could be an effective statistical system to adopt for cost minimization purpose (Tam \& Clarke, 2015).

\section{Relay Accurate and Real-Time Information:}

With the management of sectoral information and citizen registration related information through respective websites, it has been evident that the users can easily access information in real-time (Bertot et al. 2016; Hilbert, 2016). However, the progress of information fill-up in both sites are not satisfactory as it is not mandatory for individuals as well as for institutions. Integrated statistical management system is mandated by integrated statistical management policy. Hence, each updated information gets compiled and displayed real-time through graphical presentation as well as numerical presentation (Kurfali et al. 2017; Rathore et al. 2018). Recently, information regarding the COVID cases was displayed in real time by ministry of health and population using different visualization techniques. It was beneficial for all concerned stakeholders to analyze the status and plan accordingly. 


\section{Link with National and Global commitments (periodic plans and Sustainable Development Goals):}

With integrated statistical management policy and system in place, government institutions can track and monitor the progress on indicators such as income level (from formal and informal employment opportunities), vulnerability status, accessibility to basic facilities (water, latrine, internet, health), education status, registration card, financial institution, social protection, etc. (Sarker et al. 2018). These statuses are linked with indicators incorporated in Sustainable Development Goals 2015-2030 and their measurement and efficient tracking can help Nepal understand its progress in various SDG milestones (Badiee et al. 2017).

\subsection{Challenges associated with Integrated Statistical Management System}

Integrated statistical management policy and system does have its own share of challenges. Literature have highlighted the case studies of countries that have adopted similar system. Some of the challenges are explained below:

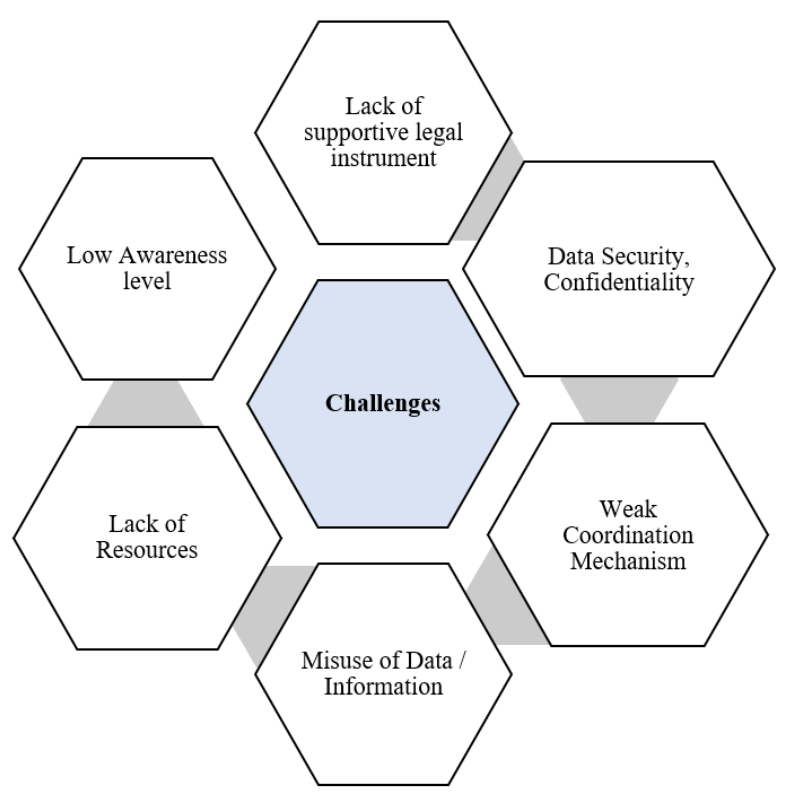

Figure 3: Identified challenges to adopt Integrated Statistical Management System

\section{Lack of supportive legal instruments:}

To have smooth implementation of integrated statistical management system requires efficient legal instruments in place. Many countries have adopted similar system but they still are struggling with legal instruments such as acts, guidelines, and strategy (Alghamdi et al., 2011; Rana et al. 2013; Yadav et al., 2020). Legal instruments can lay a foundation where each institution can be supportive in making the system operational (United Nations [UN], 2016). However, in the absence of legal enforcement, government as well as non-government institution may not comply.

\section{Data Security:}

With technological advancement, the concerns of data security have been increased in recent times (Buzzigoli \& Biggeri 2001; Giri \& Shakya 2019; Morabito 2015; Rana et al. 2013). From small to large scale organizations even at developed countries, data theft and malwares (virus) attacks have been challenging issues to deal with (Cofta 2008; Oracle 2008; Sarker et al. 2018; Yadav et al., 2020). Nepal still lags behind technologically, thus the concerns of data security remains one of the key challenges in implementing integrated policy and system (Brewer et al., 2015).

\section{Page 100}




\section{Data Confidentiality, Permissibility and Transparency:}

Integrated Statistical Management System can include wide range of statistics related to individuals, families and institutions (private or public). From individual level to institutional level, everyone can adopt the "right to information" policy and access national statistics. Thus, maintaining the confidentiality of the statistics is the prime task of the institution responsible to manage national statistics (Quintslr, 2015). A successful operation of Integrated statistical management system requires linkage and sharing of data between agencies. With availability of data, government as well as private agencies may opt to use them for their own purposes (Kasozi and Brendon, 2018). In such case, questions and debate may arise regarding who gets the permission and accessibility to data (Brewer et al., 2015; Landefeld 2014; Morabito 2015; Tam \& Clarke 2015). Considering the human right principle to maintain confidentiality of statistics related to individual, countries have adopted the system where civil related data are kept confidential from government institutions (ADB 2016; United Nations (UN) 2016). However, with ever-evolving technology and current practices of national statistical management system through diverse institutions, and ever-increasing demand of national statistics among government and private institutions, confidentiality remains the most challenging aspect of the system.

\section{Low Level of Coordination among agencies:}

Implementability of integrated statistical management system requires strong coordination among government institutions, non-government/private institutions and citizens. In current scenario, integrated approach has not been prioritized among institutions (Gautam 2016; Phuyal 2020). Low level of coordination between government agencies responsible to manage statistics; and duplication or overlapping roles among agencies remains a challenging aspect across the globe (Olubusoye et al. 2015). As each institution have their own sectoral priorities, plans and programs, integration between agencies in current scenario seems to be a daunting task.

\section{Lack of Resources (human, financial and technological):}

In recent times, Government institutions (Department of National ID and Civil Registration and Central Bureau of Statistics) have adopted digital system to register and update the databases of individual and sectoral in the form of national ID system and national statistics, respectively. Theoretically, local government is responsible to regularly update information at registration system and sectoral ministries are responsible to regularly update information at sectoral database. However, the reality is bleak (Phuyal, 2020). Rana et. al. (2013) emphasize the role of resources for the success of the system. However, in the case of Nepal, one of the major constraints faced is lack of resources either it be human, financial, or technological. Nepal is still at early stage comparing to other countries technologically, Financial resource allocation is also not very encouraging. Furthermore, it is still not considered prioritized area of government body both at federal and local levels (Gautam, 2016). With the implementation of IT Policy 2000, government institutions started adopting technologies at wider level. This also requires presence of trained human resources, however the government sector still faces shortage of skilled manpower to operate the complex system (Adhikari, 2009; Yadav et al., 2020).

\section{Awareness Level among citizen:}

If any system is to be successfully implemented, awareness level among users remains one of the key aspects. In the case of integrated statistical management system, government 
representatives and citizen are the users of those system and their awareness level plays a significant role in making the system successful (Badiee et al. 2017; Rana et al. 2013; Voutinioti 2013). It has also been observed that whenever new legal instruments and systems implemented, users take some time to get habitual with the system. It mostly depends on what level of awareness among users and promotional activities from the implementation side (Kurfali et al., 2017; Writz et al., 2018). Though multiple systems such as National ID and National sectoral database are in place, people are not that much aware about their establishment and their significance in day to day life which is also one of the underlying causes of ineffectiveness.

\section{Digital Literacy:}

Integrated statistical management system is more about digital system than manual paperbased system. Nepal is among the countries, where formal literacy is still not at satisfactory level. In the given context, making the citizens aware and habitual towards digital literacy is a challenging task for government institutions (Adhikari 2009; Writz et al. 2018). There is a possibility of citizens from remote areas being excluded from registration process due to lack of digital literacy which can further exclude them from receiving government related services and benefits (Brewer et al. 2015; Mitra 2019; Peeters \& Widlak 2018).

\section{Conclusion and Policy Recommendation}

From policy perspective, Government of Nepal have promulgated wider range of legal instruments to strengthen the civil registration, sectoral statistical management, and adoption of digital medium to store and manage the database. Individually, all those respective legal instruments have their own underlying strength and gaps. Barring Statistics Act 1958, other legal instruments have been either updated/revised or new supporting legal instrument has been formulated. In the case of Statistical management, Government of Nepal has been following the same mandate as that of Statistics Act 1958 which has not been revised or updated thus making the policy less relevant in the current settings. To mark the progress made over national and global commitments, Government of Nepal need to have documentation of real-time progress on sector-specific targets and programs, primarily to align with Sustainable Development Goal 2015-2030. Technologically, Government of Nepal have comparatively weaker statistical management system thus has been relying on multilateral and I/NGOs to carry out data collection process and present the progress. With an integrated statistical management system in place, Government of Nepal can present the progress on each sector in an independent manner. The statistics can be further utilized for designing and implementing periodic plans and programs.

Understanding the opportunity and need, both developed and developing countries in their varying capacity or ability have already initiated implementing digital mechanism to register and link with government services and facilities (Alshehri et al. 2013; Peeters \& Widlak 2018; Rokhman 2011; Sagarik et al. 2018; Third et al. 2018). Some of the noticeable systems similar to the context of Nepal include Computerized National Identity Card (CNIC) from Pakistan, Unique Identification or Adhar from India, Estonian Id Card, smart national identity card from Bangaldesh, National Identification System from Iraq, etc. (Datta et al. 2020; Jabbar et al. 2013; Kalja et al. 2015; Mali \& Avila-Maravilla 2018; Ullah et al. 2015).

From Policy perspective after the promulgation of the Constitution of Nepal 2015, Government of Nepal has already set the foundation to adopt digital technology in order to

\section{Page $\mid 102$}


register individuals as well as to link with various sectors of the government In current setting, sectoral and civil registration systems are operationalized under their respective policies by different government agencies. This can be taken as one of the noticeable gaps in implementing the integrated statistical management system.

Analyzing the scope of integrated statistical management system and past trend of priorities set by the Government of Nepal, this paper strongly recommends for the update of Statistics Act (1958) and emphasizes on the use of Integrated Statistical Management System.

a. Update Statistics Act 1958: National Statistical System (NSS) is functional based on Statistics Act 1958. Over the 60 years period, statistical management approach has its own share of success and failures. However, with ever-increasing demand of the national statistics and advanced technologies at global level, Government of Nepal should immediately initiate a process towards updating statistics act 1958. Similar to the strategy adopted to reform the Birth, Death and Other Personal Events (Registration) Act and Rules into National ID and Registration Act 2019, Statistics Act 1958 should move towards either updating or reforming the Act.

b. Manage national statistics under single institution: As of 2021, government as well as non-government agencies have been managing statistics based on their needs and requirements. It is inefficient; increases the overlapping of the statistics and also reduces the trust among public or end-users towards national statistics. Instead, adopting the modality of integrated statistical management system, a single institution should be established and made responsible to manage all national statistics either it be sector-based statistics or vital event registrations. Having a single institution helps to form a uniform, consistent, responsive, reliable and effective statistical management system. It further helps citizen as well as other agencies to coordinate with a single institution to seek statistics as per their requirements.

c. Establish specialized agencies to manage sectoral statistics: Integrated statistical management system requires strong coordination, communication and support from diverse sector-based agencies ranging from thematic areas such as health, education, finance, information technology, civil registration, etc. The issues as stated in challenges section are also more or less due to having diverse agencies under different legal instruments and government ministries. To reduce the issues associated with coordination and linkage, the study suggests to have a provision of different sectoral agencies under single institution (ministry). The sectoral departments could be decided based on the areas of national interests along with the national and global commitments. To ensure the safety and security of the public data or big data, a specialized department has to be established under the single agency (as stated on point b.). Other existing sectoral ministries can carry out the designing and implementation of sector-specific interventions.

d. Allocate resources for infrastructure set-up: To establish a strong national statistics management system, the government needs to invest for infrastructure set up. That includes infrastructures for collection, compilation, processing, analyzing, visualizing and safe repository of the larger set of collected data i.e. big data. It also requires, strong set of layouts to ensure the safety and security of national statistics. As of now, government prioritizes more towards set-up of IT structures and capacity 
building to human resources. With this, policy should focus towards investment on assuring safety and security of data through strong data warehouse or repository mechanism under complete control of government institution.

e. Ensure Data Quality: National statistics requires wider range of data from diverse sectors including that of individuals and households. Similarly the use of national statistics is not only limited for the purpose of government-led planning and budgeting process but also to update the progress on national and global level indicators i.e. Sustainable Development Goals (SDG) etc.. Thus, data quality remains one of the challenging areas in managing national statistics. As of now, there has not been well-defined and articulated legal instrument focused towards data quality assurance. Thus, during the update or reform of statistics act 1958, data quality assurance (DQA) needs to be well articulated. Meanwhile, a separate guiding document stating the process to functionalize the opted Data Quality Assurance tools shall be prepared and published.

f. Prioritize on national statistics related awareness campaign: National statistical system can only be said to be effective, if users (citizen) know about its existence and use them on frequent manner.. Most of the Nepali legal instruments are focused towards the process and legal provisions for institution set-up, management strategy, roles and responsibilities of the committees, etc. The component related with sensitization of national statistical system is often ignored. Thus, to have an effective system from user perspective, clear strategies should be incorporated within legal instruments to carry out sensitization events on national statistical management system at federal, provincial and local level.

\section{Limitations of the Study}

Different countries adopted different principles and theoretical approaches to develop their national statistical system and/or national identification system. Each sector can have their own set of guiding theories, that have been overlooked while preparing this paper. The study limits itself to the fundamental aspects of the aforementioned systems and focuses more on opportunities and barriers that could be applicable for policy level recommendations. The study explains fundamental concepts about the existing systems adopted at global scenario in surficial level, thereby providing an opportunity for future researchers to delve into in-depth analysis and findings focusing on individual sector specific principles, theories and systems.

\section{Reference}

Adhikari, G. P. (2009). Issues in national identification database system of Nepal. In Proceedings of the 3rd international conference on Theory and practice of electronic governance (pp. 333-329).

Alghamdi, I. A., Goodwin, R., and Rampersad, G. (2011). E-government readiness assessment for government organizations in developing countries. Computer and Information Science, 4(3), 3. doi:10.5539/cis.v4n3p3

Alshehri, M., Drew, S., and AlGhamdi, R. (2013). Analysis of citizens acceptance for e-government services: applying the UTAUT model. arXiv preprint arXiv:1304.3157. 
Aritonang, D. M. (2017). The Impact of E-Government System on Public Service Quality in Indonesia. European Scientific Journal, ESJ, 13, 35-99. doi:10.19044/esj.2017. v13n35p99

Arora, S. (2008). National e-ID card schemes: A European overview. Information Security Technical Report, 13(2), 46-53. doi: 10.1016/j.istr.2008.08.002

Asian Development Bank [ADB]. (2016). Identity for Development in Asia and the Pacific. Asian Development Bank.

Atick, J. (2016). Digital identity: the essential guide. In ID4Africa Identity Forum.

Badiee, S., Jütting, J., Appel, D., Klein, T., and Swanson, E. (2017). The role of national statistical systems in the data revolution. Development Co-operation Report 2017: Data for Development.

Barde, S. (2018). A Multimodal Biometric System-Aadhar Card. i-manager's Journal on Image Processing, 5(2), 1. doi:10.26634/jip.5.2.14312

Bertot, J., Estevez, E., and Janowski, T. (2016). Universal and contextualized public services: Digital public service innovation framework.

Breckenridge, K. (2005). The biometric state: The promise and peril of digital government in the new South Africa. Journal of Southern African Studies, 31(2), 267-282. doi:10.1080/03057070500109458

Brewer, M., Menzies, N., and Schott, J. (2015). Identification Systems Don't Always Serve the Bottom 40\%. Just Development, World Bank.

Buzzigoli, L., and Biggeri, L. (2001). Statistical Disclosure Control and Data Access for Research Purposes: Critical Issues and Possible Solutions. Bulletin of the International Statistical Institute, 53 rd Session, Proceedings, 59, 257-260.

Central Bureau of Statistics [CBS], (2017). A compendium of National Statistical System of Nepal. Kathmandu, Nepal: Central Bureau of Statistics.

Cofta, P. (2008). Towards a better citizen identification system. Identity in the Information society, 1(1), 39-53. doi: 10.1007/s12394-009-0006-6

Dass, R., and Bajaj, R. K. (2008). Creation of a Single National ID: Challenges \& Opportunities for India [W.P. No. 2008-08-04].

Dennison, L., and Rana, P. (2017). Nepal's emerging data revolution. http:/ /devinit.org/ wp-content/uploads/2017/04/Nepals-emerging-data-revolution.pdf

Gautam, R. B. (2016). Civil Registration and Vital Statistics: Policy and Practices in Nepal, Department of Civil Registration

Gelb, A. and Diofasi, A. (2016). Using Identification for Development: Some Guiding Principle [CGD Notes], Center for Global Development. http://www.cgdev.org/publication/ usingidentificationdevelopmentsomeguidingprinciples

Geteloma, V., Ayo, C. K., and Goddy-Wurlu, R. N. (2019, December). A Proposed Unified Digital Id Framework for Access to Electronic Government Services. Journal of Physics: Conference Series, 1378(4), 042039.

Giri, S., and Shakya, S. (2019). E-government Use in Nepal: Issues of Database Management and Data Security. Journal of the Institute of Engineering, 15(2), 218-224. doi:10.3126/jie. v15i2.27669 
Greenleaf, G., and Suriyawongkul, A. (2018). Thailand's Draft Data Protection Bill: Many Strengths, Too Many Uncertainties. Too Many Uncertainties (May 20, 2018), 153, 23-25. https:/ / ssrn.com/abstract $=3227862$

Gupta, J., and Vegelin, C. (2016). Sustainable development goals and inclusive development. International environmental agreements: Politics, law and economics, 16(3), 433-448. doi: 10.1007/s10784-016-9323-z

Hilbert, M. (2016). Big data for development: A review of promises and challenges. Development Policy Review, 34(1), 135-174. doi: 10.1111/dpr.12142

Jabbar, W., Ramasamy, A., and Othman, M. (2013, August). Citizen identification system of Iraq: Challenges and barriers in enabling e-government services. In 4 th International Conference on Computing and Informatics (pp. 404-399).

Kasozi, D. N., Brandon III, C., and Madaya, N. (2018) Repositioning Users as key drivers for Statistical Quality Assurance in Africa. International Journal of Quality Assurance and Management, 8(1), 9-16.

Kalja, A., Robal, T., and Vallner, U. (2015, August). New generations of Estonian eGovernment components. In 2015 Portland International Conference on Management of Engineering and Technology (PICMET) (pp. 631-625). IEEE.

Kitchin, R. (2015). Big data and official statistics: Opportunities, challenges and risks. Statistical Journal of the International Association of Official Statistics, 31(3), 471-481.

Khan, A. (2018). National Identity Card: The Dilemma between Social Opportunities and Threats. International Journal of Multidisciplinary Studies, 5(1). doi:10.4038/ijms.v5i1.108

Kurfalı, M., Arifoğlu, A., Tokdemir, G., and Paçin, Y. (2017). Adoption of e-government services in Turkey. Computers in Human Behavior, 66, 168-178.

Landefeld, S. (2014, October). Uses of big data for official statistics: privacy, incentives, statistical challenges, and other issues. In International conference on big data for official statistics Beijing, China (pp. 30-28).

Mali, N. V., and Avila-Maravilla, M. A. (2018). Convergence or Conflict? Digital Identities vs. Citizenship Rights: Case Study of Unique Identification Number, Aadhaar, in India. In Proceedings of the 11th International Conference on Theory and Practice of Electronic Governance (pp. 448-443).

Mitra, R. (2019). Linking national ID and CRVS systems: an imperative for inclusive development [Knowledge Brief]. Centre of Excellence for CRVS Systems, 2(3).

Mohammed, M. A., Aboobaider, B. M., Ibrahim, H., Abdullah, H. A., Ali, M. H., Jaber, M. M., and Shawkat, A. (2016). E-government and its challenges in developing countries: Case study Iraqi e-government. Soc. Sci, 11(17), 4310-4319.

Morabito, V. (2015). Big data and analytics for government innovation. In Big data and analytics (pp. 45-23). Springer, Cham.

National Planning Commission (NPC, 2018). National Strategy for Development of Statistical System, National Planning Commission, Central Bureau of Statistics

Olubusoye, O.E., Keshinro, O., and Korter, G. (2015). Nigerian Statistical System: The Evolution, Progress And Challenges.

Oracle (2008). Integrating E-ID into Next-Generation Citizen Services, Oracle Corpora- 
tion

Peeters, R., and Widlak, A. (2018). The digital cage: Administrative exclusion through information architecture-The case of the Dutch civil registry's master data management system. Government Information Quarterly, 35(2), 175-183.

Phuyal, G. P. (2020) Reviewing the National Statistical System of Nepal in New Federal Structure.

Piotrowicz, W. (2015). Information technology and systems in the Visegrád group of countries (Czech Republic, Hungary, Poland, and Slovakia): A literature review. Journal of Global Information Technology Management, 18(2), 77-93. doi: 10.1080/1097198X.2015.1052684

Quintslr, M. (2015). Relationships network for viability of National Statistical Systems Motivations for a future study.

Radhakrishna, R. (2012). Indian Statistical System: Emerging Concerns and New Initiatives. Review of Development and Change, 17(2), 9-16.

Rana, N. P., Dwivedi, Y. K., and Williams, M. D. (2013). Analysing challenges, barriers and CSF of egov adoption. Transforming Government: People, Process and Policy, 7(2), 177-198.

Rathore, M. M., Paul, A., Hong, W. H., Seo, H., Awan, I., and Saeed, S. (2018). Exploiting IoT and big data analytics: Defining smart digital city using real-time urban data. Sustainable cities and society, 40, 600-610.

Rokhman, A. (2011). e-Government adoption in developing countries; the case of Indonesia. Journal of Emerging Trends in Computing and Information Sciences, 2(5), 228-236.

Sagarik, D., Chansukree, P., Cho, W., and Berman, E. (2018). E-government 4.0 in Thailand: The role of central agencies. Information Polity, 23(3), 343-353.

Salman, A. (2010). ICT, the new media (Internet) and development: Malaysian experience. The Innovation Journal: The Public Sector Innovation Journal, 15(1), 5.

Sarker, M. N. I., Wu, M., and Hossin, M. A. (2018, May). Smart governance through bigdata: Digital transformation of public agencies. In 2018 international conference on artificial intelligence and big data (ICAIBD) (pp. 70-62). IEEE.

Shrestha, R. (2019). Governance and Institutional Risks and Challenges in Nepal. Asian Development Bank. doi: 10.22617/TCS190551

Soja, P., and Cunha, P. R. D. (2015). ICT in transition economies: Narrowing the research gap to developed countries. doi:10.1080/02681102.2015.1028734

Subedi, R. S. (2020). After Spending Rs. 700 million to Identify the Poor, Nepal Still Does not Have their Database. MyRepublica, https://cutt.ly/6jaFDwP retrieved on 29 December 2020

Szabó, Z. K., and Chiriac, L. (2016). Investigations Concerning E-Government Adoption in Transition Economies. Acta Oeconomica, 66(1), 57-78. doi: 10.1556/032.2016.66.1.3

Tam, S. M., and Clarke, F. (2015). Big data, official statistics and some initiatives by the Australian Bureau of Statistics. International Statistical Review, 83(3), 436-448.

The World Bank Group. (2017). The State of Identification Systems in Africa - A Synthesis of Country Assessments. International Bank for Reconstruction and Development. https://openknowledge.worldbank.org/bitstream/handle/10986/26504/114628-W 
P-68p-TheStateofIdentificationSystemsinAfricaASynthesisofIDDAssessments-PUBLIC.pdf

Third, A., Quick, K., Bachler, M., and Domingue, J. (2018). Government services and digital identity. Knowledge Media Institute of the Open University.

Ullah, R., Abbass, M. Y., and Khattak, A. (2015). Exploring the Role of Computerized National Identity Card (Citizens' Registration Card) in Securing Women's Property Rights in Pakistan. Abasyn Journal of Social Sciences, 8, 213-29.

United Nations (UN, 2015). United Nations Fundamental Principles of Official Statistics: Implementation Guidelines, United Nations

Verhulst, S. G., and Young, A. (2017). Open data in developing economies: Toward building an evidence base on what works and how (p. 284). African Minds. http://library.oapen.org/ handle/20.500.12657/28916

Voutinioti, A. (2013). Determinants of user adoption of e-government services in Greece and the role of citizen service centres. Procedia Technology, 8, 238-244.

Yadav, et al. (2020). Data Warehouse Model for E-Governance in Nepal, Xavier International College Journal, 2(1)

\title{
Declaration of Interest
}

I wish to confirm that, there are no known conflicts of interest associated with the publication article. I hereby confirm, no funding support has been received and no agencies are associated with this article thus removing the potential conflict of interest.

\begin{abstract}
About Authors
Manish Thapa is the M. Phil Scholar on Development Studies at School of Education, Kathmandu University. He has over eight years of professional experience working in the development and humanitarian sector in a diverse portfolio focusing on research, advocacy, monitoring, evaluation and learning. He possesses an interest in researching and writing in the areas of development focused plans and policies. He was rewarded with an Excellence Award by UNEP Eco-Peace Leadership Center for leading research-based project focusing on environmental health and chemical safety in 2012/013.
\end{abstract}

